\title{
ANALISIS MODEL PENGEMBANGAN PULAU OSI DI KABUPATEN SERAM BAGIAN BARAT SEBAGAI KAWASAN WISATA BAHARI BERKELANJUTAN
}

\author{
(Analysis of Osi Island Development Model In Western Seram District As a \\ Sustainable Marine Tourism Area) \\ Patmawaty Hehanussa $^{1)}$ Muh Kasnir ${ }^{2)}$, Danial ${ }^{3)}$ \\ 1) Mahasiswa Pasca Sarjana Universitas Muslim Indonesia \\ 2) Program Studi Budidaya Perairan FPIK UMI Makassar \\ 3) Program Studi Magister Manajemen dan Teknologi Kelautan PPS UMI Makassar
}

Korespondensi: fthyhenssa@gmail.com

Diterima: tanggal 20 Maret 2020; Disetujui 25 April 2019

\section{ABSTRACT}

This study aims (1) to analyze the relationship between external and internal factors on the sustainability of the marine tourism of Osi Island and (2) formulate a model for the development of marine tourism in Osi Island. This type of research is quantitative descriptive research. Data sources are tourists who are and have been to Osi Island. Techniques used in data collection include field studies / observations and literature studies. Data analysis was performed using a strucktural equation model (SEM) analysis with AMOS analysis tools. The results showed that: (1) Variable internal and external factors significantly influence the sustainability of tourism on Osi Island where human resources are more dominant to contribute to this due to community awareness in the local village in terms of maintaining cleanliness and managing existing nature. Based on this it can be said that in terms of environmental aspects the marine tourism area of Osi Island has fulfilled what is said to be sustainable. (2) the final model of this research is interpreted for the future development plan of Osi Island where the development plan must be based on the vision of sustainable tourism and because Osi Island is a self-managed tourism area, it can develop a community-based tourism model with all stakeholders related namely the central government, local government, etc. can participate in the development both directly and indirectly so that the impact of the development of the model results in an independent community from all aspects.

Keywords : SEM, Osi Island, Development Model

\section{ABSTRAK}

Penelitian ini bertujuan (1) menganalisa hubungan antara faktor eksternal dan internal terhadap keberlanjutan wisata bahari pulau osi dan (2) merumuskan model pengembangan wisata bahari Pulau Osi. Jenis penelitian ini adalah penelitian deskriptif kuantitatif. Sumber data adalah wisatawan yang sedang dan pernah berkunjung ke Pulau Osi. Teknik yang digunakan dalam pengumpulan data meliputi studi lapangan/observasi dan studi kepustakaan. Analisis data yang dilakukan menggunakan analisis strucktural equation (SEM) dengan alat analisis AMOS. Hasil penelitian menunjukkan bahwa: (1) Variabel faktor internal dan eksternal berpengaruh signifikan terhadap keberlanjutan wisata di Pulau Osi dimana sumber daya manusia lebih dominan memberi kontribusi hal ini dikarenakan adanya kesadaran masyarakat di desa setempat dalam hal menjaga kebersihan dan mengelola alam yang sudah ada. Berdasarkan hal tersebut dapat dikatakan secara aspek lingkungan kawasan wisata bahari Pulau Osi sudah memenuhi untuk dikatakan berkelanjutan. (2) model akhir dari penelitian ini di interpretasikan Untuk rencana pengembangan Pulau Osi kedepan dimana dalam rencana pengembangan harus berdasarkan pada visi pariwisata berkelanjutan dan Karena Pulau Osi merupakan kawasan wisata yang dikelola sendiri oleh masyarakat setempat maka dapat dikembangkan model wisata berbasis masyarakat dengan seluruh stakeholders yang terkait yaitu pemerintah pusat, Pemda dll dapat berperan serta dalam pengembangan tersebut baik secara langsung maupun tidak sehingga dampak dari pengembangan model tersebut menghasilkan masyarakat yang mandiri dari segala aspek.

Kata kunci : SEM, Pulau Osi, Model Pengembangan 



\section{PENDAHULUAN}

Pemanfaatan dan pengembangan sumberdaya perairan menjadi paradigma baru yang perlu direalisasikan secara optimal dengan di dukung oleh potensi yang dimiliki di wilayah Indonesia. Dengan berkembangnya sector pariwisata di suatu daerah akan mempengaruhi pendapatan di daerah tersebut serta memberikan kesejahtraan kepada masyarakat.

Kabupaten Seram Bagian Barat merupakan salah satu kabupaten hasil pemekaran berdasarkan undang-undang nomor 40 tahun 2003, yang semula merupakan bagian dari Kabupaten Maluku Tengah. Kabupaten Seram bagian Barat memiliki 62 buah pulau dengan jumlah pulau yang berpenghuni sebanyak 10 buah pulau dan 52 buah lainnya yaitu yang tidak berpenghuni. Sebagian wilayahnya yang merupakan perairan laut memberikan luas untuk pengembangan potensi wisata bahari yang dapat memberikan revenue terhadap ekonomi masyarakat.

Pulau Osi merupakan salah satu Destinasi Unggulan yang berada di kabupaten Seram Bagian Barat. II CITES. Namun dengan potensi dan Kawasan tersebut juga masih termasuk keindahan laut yang dimiliki, Pulau ini daerah Taman Wisata Alam Laut Pulau
Marsegu dengan lokasi hanya sekitar 9 Ha, panjang 600 meter dan Lebar sekitar 200 meter. Meskipun Pulau ini Kecil namun memiliki daerah sekitar yang mempunyai potensi hasil laut yang baik. Daerah dengan terumbu karang yang beragam sebagai habitat dari berbagai jenis ikan yang merupakan sebuah tempat pariwisata dengan beberapa pulau tak berpenghuni (tatobalambunte, tatobalasungke, tatobosurati, dan tatobobensin) yang masih asri. Menjadikan pulau ini tampak berbeda dari yang lainnya.

Keunikannya berupa pesona alam sekitar pantai yang masih terlihat asri dan alami disertai dengan jembatan penghubung antara Pulau Osi dan Pulau Seram yang terbuat dari kayu sepanjang $2 \mathrm{~km}$ dan lebar tidak lebih dari 2 meter dengan dikelilingi mangrove yang berjejer rapi sepanjang jembatan serta airnya yang sangat jernih membuatnya terlihat seperti aquarium raksasa karena dapat melihat secara langsung berbagai jenis ikan yang berwarna warni, salah satunya yaitu ikan Napoleon yang termasuk jenis ikan yang yang dilindungi dan masuk dalam appendiks masih minim dalam hal 
mengembangkan kegiatan wisatanya, teknik analisis structural equation Permasalahan lain yaitu kurangnya model (SEM). SEM merupakan atraksi wisata, aksesbilitas, sarana dan gabungan dari dua metode statistic prasarana serta minimnya hardscape yang terpisah yaitu analisis factor sebagai penunjang kegiatan wisata. (factor analysis) yang dikembangkan di Pulau osi hanya menyediakan atraksi ilmu psikolog dan psikometri dan berenang, dan memandangi sunset model persamaan simultan (Priambudi, 2016). Padahal dengan (simultaneous equation modeling) yang adanya berbagai jenis ekosistem dikembangkan di ekonometrika (terumbu karang, lamun, mangrove, (Ghozali, 2005).

pantai berbatu) dapat menjadikan pulau

osi lebih baik jika dikembangkan secara optimal.

Pemerintah daerah telah membuat strategi guna pengembangan wisata bahari di Pulau Osi namun selama ini nyatanya belum optimal. Permasalahan mendasarnya adalah belum maksimalnya tahapan analisis faktor lingkungan baik internal maupun eksternal (Priambudi, 2016).

Melihat permasalahan tersebut peneliti tertarik untuk menganalisa model pengembangan Pulau Osi di Kabupaten Seram Bagian Barat sebagai kawasan wisata bahari berkelanjutan yang diharapkan dapat menjadikannya sebagai kawasan destinasi pariwisata yang berdaya saing tinggi serta menjadi contoh untuk pengembangan pariwisita daerah lain yang ada di Maluku. Oleh karena itu, peneliti akan menggunakan

\section{METODE PENELITIAN}

Penelitian ini dilaksanakan selama dua bulan yaitu pada bulan September - Oktober 2019 bertempat di Pulau Osi Kabupaten Seram Bagian Barat Provinsi Maluku.

Sampel yang digunakan pada penelitian ini mengacu pada teori Ferdinand (2012), yang menyarankan ukuran sampel yang sesuai untuk alat analisis SEM adalah antara $100-200$ responden dengan maksud agar dapat digunakan dalam mengestimasi interpretasi dengan SEM. Penetuan sampel tersebut menggunakan rumus Slovin dan menghasilkan jumlah sampel pada penelitian ini sebanyak 119 orang dengan teknik purposive sampling dimana responden yang dipilih adalah semua wisatawan yang sedang dan pernah mengunjungi Pulau 
Osi kurang dari 6 bulan terakhir. Data (analysis Moment of structure) Ver. 26 yang telah dikumpulkan kemudian dengan gambar pola hubungan antar diolah dengan bantuan Software AMOS variable pada Gambar 1.

Model Persamaan Struktural

\begin{tabular}{|l|}
\hline Model Persamaan Struktural \\
\hline Daya Tarik Wisatawan $=\beta 1$ faktor internal $+\beta 2$ faktor eksternal $+\delta 1$ \\
\hline Faktor eksternal $=$ faktor internal $+\delta 2$ \\
\hline
\end{tabular}

Persamaan structural model faktor $\delta=\left(\delta_{19}, \delta_{20}, \delta_{21}\right)$

internal adalah sebagai berikut:

\section{Keterangan:}

$\mathrm{X}=\Lambda_{\mathrm{x}} \xi+\delta$

$\mathrm{X}=$ vektor - vektor peubah indikator

$\mathrm{x}$

$\left(X_{1}, \quad\right.$ yang dapat diamati secara langsung

$\left.X_{2}, X_{3}, X_{4}, X_{5}, X_{6}, X_{7}, X_{8}, X_{9,} X_{10}, X_{11}, X_{12}\right)$

$\xi=$ vector peubah laten bebas (laten

$\xi=\xi_{1}$ eksogenous)

$\Lambda_{\mathrm{x}}=\left(\lambda_{1}, \lambda_{2}, \lambda_{3}, \lambda_{4}, \lambda_{5}, \lambda_{6}, \lambda_{7}, \lambda_{8}, \lambda_{9}, \lambda_{10}, \delta=\right.$ vector galat pengukuran dari y dan

$\lambda_{\left.11, \lambda_{12}\right)}$ $\mathrm{x}$ dengan ukuran masing-masing qxl

$\delta=\left(\delta_{1}, \delta_{2}, \delta_{3}, \delta_{4}, \delta_{5}, \delta_{6}, \delta_{7}, \delta_{8}, \delta_{9}, \delta_{10}\right.$

$\Lambda_{\mathrm{X}}=$ matriks berukuran qxn

$\delta_{\left.11, \delta_{12}\right)}$

$\mathrm{X} 1=$ Faktor Internal

Persamaan structural model faktor $\mathrm{X} 2=$ Faktor Eksternal

eksternal adalah sebagai berikut:

X3 = Daya Tarik Wisatawan

$\mathrm{X}=\Lambda_{\mathrm{x}} \xi+\delta$

Untuk memperoleh sebuah

$\mathrm{x}=\left(X_{13}, X_{14}, X_{15}, X_{16}, X_{17,} X_{18}\right)$

model yang fit perlu adanya Pengujian

$\xi=\xi_{2}$ terhadap berbagai kriteria goodness of

$\Lambda_{\mathrm{x}}=\left(\lambda_{13}, \lambda_{14}, \lambda_{15}, \lambda_{16}, \lambda_{17}, \lambda_{18}\right)$ fit, setelah dipastikan bahwa data yang $\delta=\left(\delta_{13}, \delta_{14}, \delta_{15}, \delta_{16,} \delta_{17}, \delta_{18}\right)$ digunakan sudah memenuhi asumsiPersamaan structural model faktor asumsi SEM. Setelah melakukan uji daya tarik wisatawan adalah sebagai kesesuaian dan uji statistic, beberapa berikut: indeks kesesuaian dan cut-off value

$\mathrm{X}=\Lambda_{\mathrm{x}} \xi+\delta$ yang umumnya digunakan untuk $\mathrm{x}=\left(X_{19}, X_{20}, X_{21}\right)$ menguji apakah sebuah model akan

$\xi=\xi_{2}$ diterima atau ditolak, yaitu (Wijanto, $\Lambda_{\mathrm{x}}=\left(\lambda_{19}, \lambda_{20}, \lambda_{21}\right)$ 2008) 



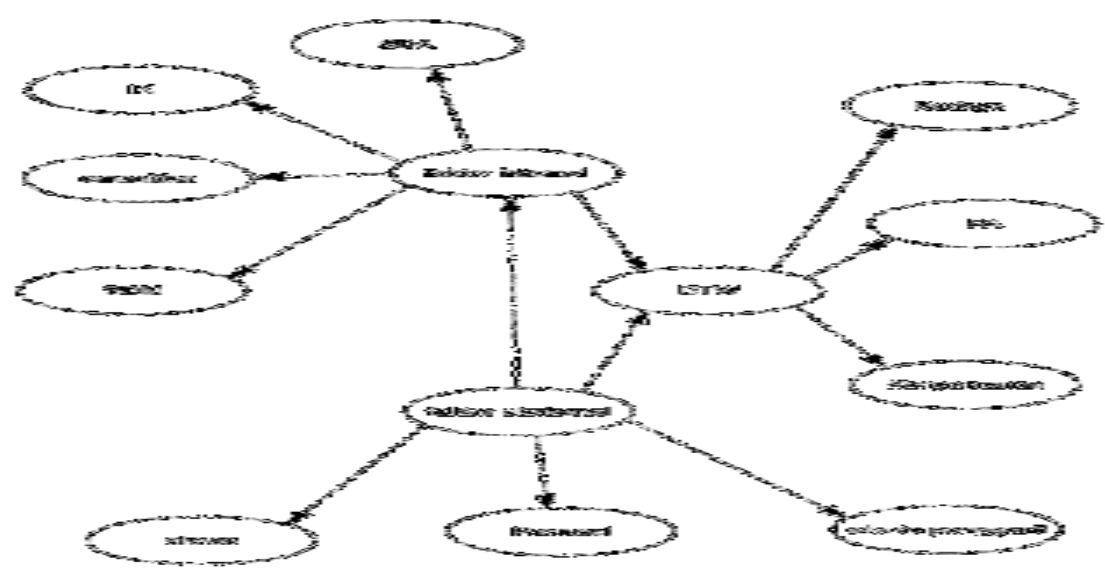

Gambar 1. Hubungan antara variable

Variable Faktor Internal ini mulai terkenal sejak masyarakat merupakan variable eksogen yang membangun jembatan kayu sepanjang memiliki 12 indikator atau variable $2 \mathrm{~km}$ pada tahun 2007. Jembatan inilah teramati (observed variable). yang menjadi Pesona utama di Pulau Sedangkan untuk Variabel Faktor Osi sebelum wisatawan mendapatkan Eksternal merupakan variable eksogen pesona-pesona pemandangan yang dengan indikator teramatinya sebanyak menjadi daya pikat di kawasan tersebut. 6 indikator dan Variabel Daya tarik Menurut Petter (1996), faktor wisatawan yang merupakan variable internal merupakan sumberdaya suatu eksogen dengan indikator teramatinya perusahan yang akan menentukan sebanyak 3 indikator.

\section{HASIL DAN PEMBAHASAN}

Pulau Osi merupakan sebuah pulau yang dijadikan salah satu destinasi wisata oleh masyarakat setempat dan cukup dikenal dan setelah Pantai Ora di Provinsi Maluku. Pulau ini terletak di Desa Eti Kecamatan Seram Barat, Kabupaten Seram Bagian Barat dengan luas $9 \mathrm{Ha}$ dan panjang 600 meter serta lebar 200 meter. Pulau kekuatan dan kelemahan perusahan tersebut,sumberdaya yang dimaksud adalah SDM SD Perusahan, SDA, dan SD Fisik, apabila perusahan dapat mengoptimalkan pengguna sumberdaya tersebut maka sumber daya diatas mampu memberikan keberhasilan dan keunggulan bersaing. Maka dalam penelitian ini di tentukan bahwa faktor internal mampu memberikan kontribusi atau pengaruh terhadap daya tarik 
wisatawan untuk evaluasi eksternal melalui aksesbilitas dan pengembangan kawasan wisata melalui promosi, mampu memberikan interaksi Sumber daya manusia, sumber kontribusi dalam pengembangan daya alam, citra kawasan, dan pariwisata. amenities.

Menurut Gunn (2002), dalam pengembangan dan perencanaan pariwisata tidak hanya terkonsentrasi pada hal komponen pariwisata, yaitu tourist attraction dan tourist service tetapi terdapat faktor - faktor eksternal yang memiliki dampak yang besar dalam perencanaan pengembangan pariwisata, penetapan fungsi wisata, dan kritik perencanaan pariwisata. Pada penelitian ini ditentukan bahwa faktor
Menurut Pendit (2000), daya tarik wisatawan merupakan segala sesuatu yang menarik dan bernilai untuk di kunjungi dan dilihat. Pada penelitian ini ditentukan bahwa daya tarik wisatawan dengan melalui dimensi pendukungnya sendiri yaitu budaya, pemandangan atau keindahan alam, dan kenyamanan wisatawan mampu mempengaruhi daya tarik kawasan itu sendiri.

Hasil uji model awal hubungan antara variable di tampilkan pada Tabel 1.

Tabel 1. Uji kelayakan model awal

\begin{tabular}{lccc}
\multicolumn{1}{c}{$\begin{array}{c}\text { Goodness of Fit } \\
\text { Index }\end{array}$} & Cut of Value & Hasil & Evaluasi Model \\
\hline X2 - chi Square & Diharapkan kecil & 430,064 & Buruk \\
\hline $\begin{array}{l}\text { Significance } \\
\text { Probability }\end{array}$ & $\geq 0.05$ &, 000 & Marginal \\
\hline RMSEA & $\leq 0.08$ &, 105 & Buruk \\
\hline GFI & $\geq 0.90$ &, 740 & Marginal \\
\hline AGFI & $\geq 0.90$ &, 677 & Buruk \\
\hline CMIN/DF & $\leq 2.00$ & 2,312 & Buruk \\
\hline TLI & $\geq 0.95$ &, 523 & Buruk \\
\hline CFI & $\geq 0.95$ &, 577 & Buruk \\
\hline Keterangan: & & & \\
\hline RMSEA & $:$ Root Mean Square Error of Approximation & \\
\hline GFI & $:$ Goodness-of-Fit Index & \\
\hline AGFI & $:$ Adjusted Goodness of Fit Index & \\
\hline CMIN/DF & $:$ The Minimum Sample Discrepancy & Function/Degree of \\
\hline \multicolumn{4}{l}{ Fredom } \\
\hline CFI & $:$ Tucker-Lewis Index & \\
\hline
\end{tabular}



Uji awal pada penelitian ini kesalahan pengukuran indikator. memperoleh model yang tidak sesuai Modifikasi model dengan mengikuti dengan kriteria yang ditetapkan, sebab nilai MI diharapkan dapat menurunkan dari tidak fitnya model dikarenakan ada nilai chi-square apabila covariance dari kemungkinan beberapa indikator dari indikator - indikator dikorelasikan, variabel yang mempengaruhinya yang selanjutnya mengkorelasikan variabel seharusnya tidak dipakai atau variabel yang memiliki nilai MI yang dimasukan kedalam penelitian. Hal terbesar dengan syart nilainya lebih tersebut di perkuat oleh Danial (2011), besar dari 4 (MI $\geq 4$ ), sampai menyatakan bahwa Indikator variabel memperoleh model yang dianggap laten dalam model secara sistematik benar-benar fit. Setelah mengkorelasi kemungkinan dipengaruhi oleh sebuah variabel - variabel berdasarkan faktor yang secara eksplisit tidak covariances MI maka di peroleh model dimasukan kedalam model, sehingga yang akan ditampilakan pada gambar 2. sangat mungkin terjadi korelasi antara

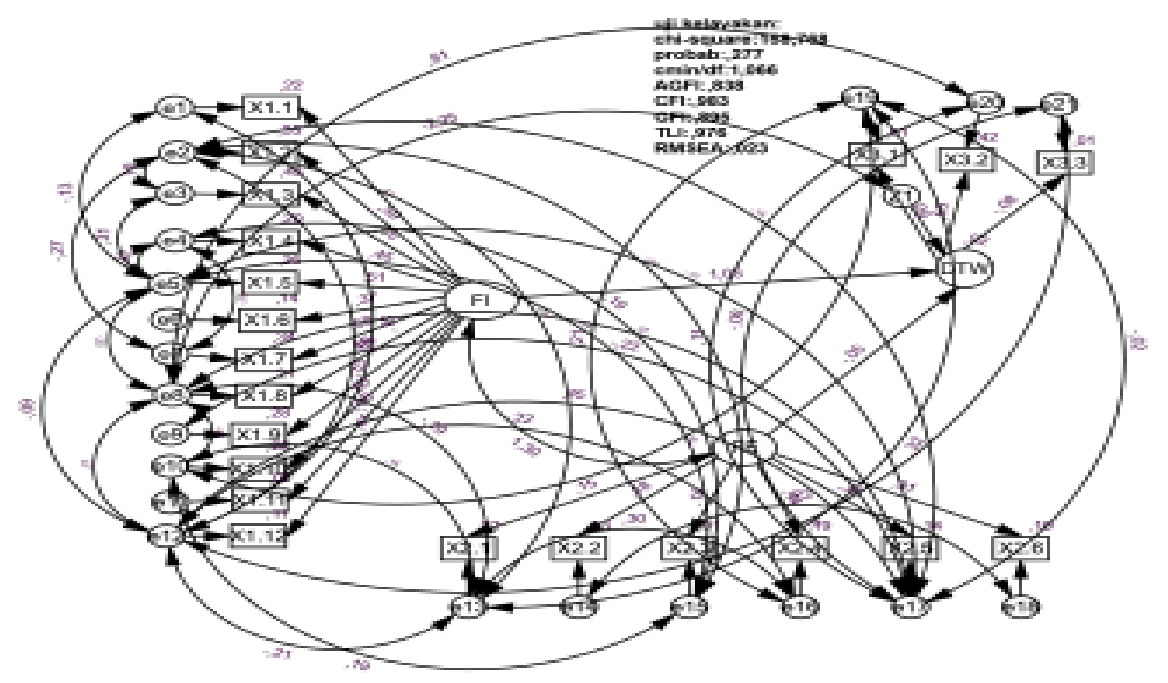

Gambar 2. Model Akhir Uji Kelayakan

Dengan melihat hasil evaluasi yang diterima dan di pakai sebagai model hanya ada beberapa nilai yang model alternatif antara hubungan faktor menunjukan marginal namun hal internal dan eksternal terhadap daya tersebut masih dikatakan layak untuk taik wisatawan di Pulau Osi sebagai sebuah model, sehingga model inilah 
salah satu media Evaluasi pesaing bagi Pulau Osi. Hal ini sesuai pengembangan. dengan hasil penelitian dimana

Hubungan faktor internal ke daya sebanyak68\% pengunjung atau tarik wisatawan serta hubungannya wisatawan menyatakan bahwa dengan faktor eksternal adalah bermunculan wisata pengganti yang hubungan signifikan dengan terjangkau biaya dan memiliki nuansa memberikan kontribusi yang positif, yang tidak jauh berbeda dengan di hubungan keduanya dapat dilihat pada Pulau osi. Kondisi seperti ini tabel 10 nilai critical rasio pada setiap diharapkan mampu mendorong variabel meunjukan angka yang baik pemerintah daerah agar dapat dengan probability yang sangat baik mengambil alih pengelola wisata Pulau dan sumber daya manusia yang paling Osi untuk dikembangkan lebih baik berkontribusi pada faktor internal lagi, serta mengembangkan ide - ide dalam pengembangan wisata di Pulau yang kreatif dan inovatif sehingga Osi, hal ini dikarenakan pemerintah keberadaannya tidak tergeser oleh yaitu dari Dinas Pariwisata Kabupaten kemunculan berbagai wisata bahari Seram Bagian Barat cukup sukses yang baru yang berada di luar daerah dalam memberikan pelatihan kepada dan juga dibuatkan peraturan pengelola wisata Pulau Osi. Hasil peraturan daerah yang mengatur terkait penelitian ini memberikan justifikasi pengembangan Pulau.

terhadap peneliti terdahulu, yang

Hasil penelitian ini memberikan menyimpulkan bahwa pengembangan justifikasi terhadap penelitian wisata bahari dibentuk dengan faktor sebelumnya yang menyatakan internal diantaranya yaitu sumber daya lingkungan eksternal diantaranya manusia, sarana prasarana dan objek dibentuk oleh persingan harga wisata (Syahadat, 2005). （Koestanto, 2010). Dalam Dari keenam indikator perkembangan Pulau Osi ternyata pembentuk faktor eksternal, faktor faktor eksternal berpengaruh signifikan Biaya yang paling kuat mempengaruhi terhadap daya tarik wisatawan untuk atau membentuk faktor eksternal. bisa berkunjung kembali.

Dewasa ini banyak bermunculan Penelitian diketahui ketiga berbagai wisata bahari yang menjadi indikator daya tarik wistawan 
mempunyai kontribusi sebagai memberikan Dampak yang sangat baik pembentuk variable itu sendiri. sehingga meningkatkan minat Penelitian ini melahirkan sebuah kunjungan wisatawan.

kesamaan dan justifikasi penelitian SARAN

Suradnya (2005), yang berhasil Berdasarkan kesimpulan diatas, mengidentifikasi faktor daya tarik bagi maka disarankan sebagai berikut:

wisatawan, budaya dalam berbagai

1. Terus dilakukannya pelatihan bentuk manifestasinya, pantai dengan segala daya tariknya, kenyamanan berwisata, kesempatan luas untuk relaksasi,keindahan alam dan keramahan penduduk.

\section{KESIMPULAN}

Berdasarkan hasil penelitian dan pembahasan,maka dapat ditarik kesimpulan bahwa pengembangan Pulau Osi sebagai objek pariwisata kabupaten Seram Bagian Barat dilakukan oleh Masyarakat belum sepenuhnya optimal. Hal ini dikarenakan adanya masalah antara Pemerintah dan juga Masyarakat yang merupakan pengelola Pulau osi yang menutup peluang bagi pemerintah untuk mengembangkan potensi lain yang dimiliki pulau osi untuk dapat dikelola dengan baik. Namun peran Dinas Kebudayaan Pariwisata, Pemuda dan Olahraga cukup membantu dalam meningkatkan Sumberdaya Manusia baik secara kualitas maupun kuantitas kepada masyarakat, Monitoring dan Evaluasi terhadap peserta pelatihan Agar makin meningkatnya pemahaman masyarakat tentang wisata

2. Hendaknya masyarakat dan pemerintah dapat mencari solusi yang tepat dalam menangani konflik yang terjadi selama ini untuk bisa mendapatkan titik yang baik dalam hal mengelola dan mengembangkann potensipotensi lain yang dimiliki Pulau osi.

\section{UCAPAN TERIMAKASIH}

Penulis mengucapkan terimakasih kepada semua pihak yang telah membantu penulis dalam menyelesaikan penilitian dan penyusunan Tesis ini, terkhusus kepada Pemerintah Kabupaten Seram Bagian Barat dan Masyarakat Pulau Osi yang membantu selama penelitian. dan Juga Promosi yang terus dilakukan 
DAFTAR PUSTAKA

Arikanto, Suharsimi (2010). Manajemen Penelitian. Halaman 134, Jakarta, Rineka Cipta.

Bagozzi, R P and Yi, Y (1998). "On the Evaluation of Structural Equation Models". Journal of Academy Marketing of Science, $16 \quad$ (1), 74-94. Retrieved January 03,2013 from.

http://down.cenet.org.cn/upfile/47/2008 61817318109.pdf

Creswell, J.W. (2014). Research Design Qualitative, Quantitative and Mixel Methods Approaches. 4 edition, London. Sage

Couper, Donald R.C \& William Emory. (1995). Metode Penelitian Bisnis. Jakarta: Erlangga

Crouh, Geoffrei I. 2016. Expert Judgment of Destination Compotitiviness Attributs. Mealbourn: La Trobe University, School of Business. Mealbourn.

Danial. 2011. Model Pengembangan Industri Perikanan Berbasis Pelabuhan Perikanan. Disertasi (Tidak Dipublikasikan). Bogor: Institut Pertanian Bogor Sekolah Pascasarjana. Program Studi Sistem dan Pemodelan Perikanan Tangkap. 169 hal.

Gunn, Clare A. 2002. Tourism Planning. New York City : Taylor and Francis
Rahmatina. D., 2014. Pemodelan Structural Equation Modelling (SEM) pada Data Ordinal dengan Menggunakan Method Weighted Least Square (WLS). Universitas Maritime Raja Ali Haji. (diakses pada 4 juli 2019)

Dinas Pariwisata Kabupaten Seram Bagian Barat. 2019. Data Pengujung.

Ferdinand, A. 2003. Structural Equation Modelling. Penelitian Manajemen. Edisi 2, Seri Pustaka Kunci 03/BP UNDIP.

Ferdinand, A. 2012. Manajemen Pemasaran; Sebuah Pendekatan Strategi Research Paper Series, No.01/mark/01/2000.

Ghozali, Imam \& Fuad. 2005. "Structural Equation Modelling Teori, Konsep dan Aplikasi dengan Program Lisre18.54", Badan penerbit Uniiversitas Diponegoro,2005

Ghozali, Imam. 2008. Model Persamaan Struktural; Konsep dan Aplikasi dengan program AMOS 16.0. Semarang: Badan Penerbit Universitas Diponegoro.

Koestanto, D. 2010. Pengembangan Daya Tarik Wisata Goa Kreo sebagai Destinasi Unggulan di Kota Semarang. Jurnal Ilmiah Pariwisata.

Pendit, S.Nyoman. 2000. Ilmu Pariwisata Sebuah Pengantar Perdana, Jakarta: Pradaya Paramitha. 
Petterson, Kimberly. 1999. Giving a Bost to Word of Mouth Adversiting. Rought Notes. Indianapolis

Priambudi, Trie. 2016. Potensi dan Permasalahan Lanskap Pulau Osi sebagai Objek Wisata Unggulan di Kabupaten Seram Bagian Barat, Provinsi Maluku. Jurnal IPLBI.

Suradnya, I Made. 2005. Analisis Faktor-Faktor Daya Tarik Wisata Bali dan Implikasinya terhadap Perencanaan Pariwisata Daerah Bali, Sekolah Tinggi Pariwisata Bali.

Syahadat, Epi. 2005. Faktor-Faktor Daya Tarik yang Mempengaruhi Kunjungan Wisatawan di Taman Nasional Gede Pangrang. Skripsi, Universitas Surya Kencana Cianjur.

Syahadat, Epi. 2005. Faktor-Faktor Daya Tarik yang Mempengaruhi Kunjungan Wisatawan di Taman Nasional Gede Pangrang. Skripsi, Universitas Surya Kencana Cianjur.

Wijayanto. 2008. Konsep dan Tutorial Struktural Equation Modelling dengan Lisrel 8.8. Graha ilmu, Yogyakarta 